\title{
Investigation of Cerebral
}

O-(2- $\left[{ }^{18}\right.$ F]Fluoroethyl)-L-Tyrosine Uptake in Rat Epilepsy Models

\author{
Carina Stegmayr $\odot,{ }^{1}$ Rainer Surges,,${ }^{2,3}$ Chang-Hoon Choi, ${ }^{1}$ Nicole Burda, ${ }^{1}$ \\ Gabriele Stoffels, ${ }^{1}$ Christian Filß, ${ }^{1,4}$ Antje Willuweit, ${ }^{1}$ Bernd Neumaier, ${ }^{1}$ \\ Alexander Heinzel, ${ }^{1,4}$ N. Jon Shah, ${ }^{1,2,5}$ Felix M. Mottaghy, ${ }^{4,6}$ Karl-Josef Langen ${ }^{1,4,5,6}$ \\ ${ }^{1}$ Institute of Neuroscience and Medicine (INM-4; INM-5; INM-11), Forschungszentrum Jülich, 52425, Jülich, Germany \\ ${ }^{2}$ Department of Neurology, RWTH University Aachen, Aachen, Germany \\ ${ }^{3}$ Department of Epileptology, University Hospital Bonn, Bonn, Germany \\ ${ }^{4}$ Department of Nuclear Medicine, RWTH University Hospital Aachen, Aachen, Germany \\ ${ }^{5}$ JARA - BRAIN - Translational Medicine, Aachen, Germany \\ ${ }^{6}$ Centre of Integrated Oncology (CIO), University of Aachen, Bonn, Cologne and Düsseldorf, Germany
}

\begin{abstract}
Purpose: A recent study reported on high, longer lasting and finally reversible cerebral uptake of $\mathrm{O}-\left(2-\left[{ }^{18} \mathrm{~F}\right] f l u o r o e t h y l\right)-L-t y r o s i n e ~\left(\left[{ }^{18} \mathrm{~F}\right] \mathrm{FET}\right)$ induced by epileptic activity. Therefore, we examined cerebral $\left[{ }^{18} \mathrm{~F}\right] \mathrm{FET}$ uptake in two chemically induced rat epilepsy models and in patients with focal epilepsy to further investigate whether this phenomenon represents a major pitfall in brain tumor diagnostics and whether $\left[{ }^{18} \mathrm{~F}\right] \mathrm{FET}$ may be a potential marker to localize epileptic foci.

Procedures: Five rats underwent kainic acid titration to exhibit 3 to $3.5 \mathrm{~h}$ of class IV-V motor seizures (status epilepticus, SE). Rats underwent $4 \times\left[{ }^{18} \mathrm{~F}\right] \mathrm{FET}$ PET and $4 \times \mathrm{MRI}$ on the following 25 days. Six rats underwent kindling with pentylenetetrazol (PTZ) 3 to $8 \times /$ week over 10 weeks, and hence, seizures increased from class I to class IV. $\left[{ }^{18} \mathrm{~F}\right] \mathrm{FET}$ PET and MRI were performed regularly on days with and without seizures. Four rats served as healthy controls. Additionally, five patients with focal epilepsy underwent $\left[{ }^{18} \mathrm{~F}\right] \mathrm{FET}$ PET within 12 days after the last documented seizure.

Results: No abnormalities in $\left[{ }^{18} \mathrm{~F}\right] \mathrm{FET}$ PET or MRI were detected in the kindling model. The SE model showed significantly decreased $\left[{ }^{18} \mathrm{~F}\right] \mathrm{FET}$ uptake 3 days after SE in all examined brain regions, and especially in the amygdala region, which normalized within 2 weeks. Corresponding signal alterations in $\mathrm{T}_{2}$-weighted $\mathrm{MRI}$ were noted in the amygdala and hippocampus, which recovered 24 days post-SE. No abnormality of cerebral $\left[{ }^{18} \mathrm{~F}\right] \mathrm{FET}$ uptake was noted in the epilepsy patients.

Conclusions: There was no evidence for increased cerebral $\left[{ }^{18} \mathrm{~F}\right] \mathrm{FET}$ uptake after epileptic seizures neither in the rat models nor in patients. The SE model even showed decreased $\left[{ }^{18} \mathrm{~F}\right] \mathrm{FET}$ uptake throughout the brain. We conclude that epileptic seizures per se do not cause a longer lasting increased $\left[{ }^{18} \mathrm{~F}\right] \mathrm{FET}$ accumulation and are unlikely to be a major cause of pitfall for brain tumor diagnostics.
\end{abstract}

Key words: PET, Epilepsy, Rat model, $\left[{ }^{18} \mathrm{~F}\right] \mathrm{FET}$

Correspondence to: Carina Stegmayr; e-mail: c.stegmayr@fz-juelich.de 


\section{Introduction}

Positron emission tomography (PET) using amino acid tracers is an established method for brain tumor diagnostics. The response assessment in neuro-oncology (RANO) working group recommends amino acid PET in addition to MRI for the management of patients with brain tumors [1-3] to obtain further information on differential diagnosis, tumor delineation, recurrence diagnosis, and therapy monitoring [4-7].

Epileptic seizure is a frequent onset symptom of brain tumors with an incidence of 20-40\%, while another 20 $40 \%$ of patients will experience seizures in the course of the disease. In low-grade tumors, the incidence of seizures can be $80 \%$ and more. While prophylactic anti-epileptic therapy is not recommend, it is mandatory after the first seizures. Seizure control depends on brain tumor treatment and adequate treatment with anti-epileptic drugs. The response rate of patients being seizure-free varies between 30 and $100 \%$ [8-11]. Accordingly, the majority of brain tumor patients investigated with amino acid PET will have experienced seizures prior to the examination.

Recently, Hutterer and colleagues [12] reported about a selected subgroup of ten patients (eight gliomas, one ischemic stroke, one septic encephalopathy) who had widespread and long lasting but finally reversible gyral accumulation of the amino acid analogue O- $\left(2-\left[{ }^{18} \mathrm{~F}\right]\right.$-fluoroethyl)-L-tyrosine ([ $\left.\left.{ }^{18} \mathrm{~F}\right] \mathrm{FET}\right)$. Initially, the high tracer uptake in those patients was misinterpreted as tumor recurrence, but histological confirmation and follow-up suggested that this accumulation was caused by previous or simultaneous epileptic seizures, accompanied by structural MRI changes. Those ten patients all had either a status epilepticus (SE) or several seizures per day, classified as focal aware or unaware seizures and focal to bilateral tonicclonic seizures (TCS). Interestingly, $\left[{ }^{18} \mathrm{~F}\right] \mathrm{FET}$ uptake was detectable up to several weeks after the seizures before it finally decreased.

The aim of this study was to explore whether $\left[{ }^{18} \mathrm{~F}\right] \mathrm{FET}$ accumulation is a typical and frequent phenomenon in epileptic foci and thus a major pitfall in brain tumor diagnostics. Furthermore, the question arises whether $\left[{ }^{18} \mathrm{~F}\right]$ FET PET could serve as a potential marker for epileptic foci. Therefore, cerebral $\left[{ }^{18} \mathrm{~F}\right] \mathrm{FET}$ accumulation was investigated in two different chemically induced rat epilepsy models. The first, the kainic acid (KA) model, is used as a severe SE model that is known to develop spontaneous seizures a few weeks after the SE due to neuronal loss, reactive gliosis, and mossy fiber sprouting (for an overview, see Dudek at al. [13]). The second, the pentylenetetrazol (PTZ) model, is a kindling model in which the seizures gradually increase over several weeks from mild absences to severe SE. In contrast to the KA model, few structural rearrangements and no chronically recurring seizures are described for this model (for an overview, see Gilbert at al. [14]). Furthermore, the results of the animal experiments were substantiated by $\left[{ }^{18} \mathrm{~F}\right] \mathrm{FET}$ PET scans of five patients with focal epilepsy and different seizures types within 12 days after the last video-EEG-documented seizure.

\section{Methods}

\section{Animals}

Sixteen male Sprague-Dawley rats (Envigo, Netherlands) were included in this study. All animals were handled in accordance with the Animal Research Committee of the Research Center Jülich GmbH, the German Animal Welfare Act, and the European Community Council directives regarding the protection of animals used for experimental and scientific purposes $(2010 / 63 / \mathrm{EU})$ and with permission by the local authorities (LANUV, North Rhine Westphalia, file number 84-02.04.2017.A281). The rats had a weight of $190-210 \mathrm{~g}$ at the beginning of the experiments and were kept under standard housing conditions with free access to food and water, unless they reached a body weight of 350 . Food was then restricted to keep that weight.

Six rats underwent titration with kainic acid (KA group), six rats underwent kindling with pentylenetetrazol (PTZ group), and four rats served as controls. After the experiments, the KA rats and two controls were sacrificed for immunohistochemistry.

\section{Patients}

The PET data of five patients with different forms of epilepsy and video-EEG-documented seizures prior to PET investigations (Table 1), who underwent $\left[{ }^{18} \mathrm{~F}\right] \mathrm{FET}$ PET between December 2017 and March 2019 for the exclusion of brain tumors, were retrospectively evaluated for $\left[{ }^{18} \mathrm{~F}\right] \mathrm{FET}$ accumulation due to seizures. All subjects had given prior written informed consent for their participation in the $\left[{ }^{18}\right.$ F]FET PET study and evaluation of their data for scientific purposes. The local ethics committee waived the need of approval for evaluation of retrospectively collected patient data. There was no conflict with the Declaration of Helsinki.

\section{Induction of Seizures and Timing of Imaging}

The experimental setup of the KA group is shown in Table 2. The KA titration was performed in six rats as described elsewhere [15] by repeated i.p. injections of $5 \mathrm{mg} / \mathrm{kg}$ kainic acid to induce $\geq 3$ consecutive hours of convulsive seizures. Seizures were then stopped by i.p. injection of $20 \mathrm{mg} / \mathrm{kg}$ diazepam $+50 \mathrm{mg} / \mathrm{kg}$ ketamine [16], and $2 \mathrm{ml} / 100 \mathrm{~g}$ warm lactated Ringer's solution were 
Table 1. Patient characteristics

\begin{tabular}{|c|c|c|c|c|c|}
\hline Patient & 1 & 2 & 3 & 4 & 5 \\
\hline Sex & $\mathrm{F}$ & M & $\mathrm{F}$ & M & M \\
\hline Age & 51 & 60 & 59 & 59 & 32 \\
\hline Diagnosis & $\begin{array}{l}\text { TLE of unknown origin } \\
\text { with focal aware and } \\
\text { unaware seizures }\end{array}$ & $\begin{array}{l}\text { TLE due to a } \\
\text { left-temporal } \\
\text { ganglioglioma }\end{array}$ & $\begin{array}{l}\text { Bilateral TLE of } \\
\text { unknown origin }\end{array}$ & $\begin{array}{l}\text { Bilateral TLE with } \\
\text { nocturnal focal } \\
\text { unaware and focal to } \\
\text { bilateral tonic-clonic } \\
\text { seizures }\end{array}$ & $\begin{array}{l}\text { Structural epilepsy with } \\
\text { focal to bilateral } \\
\text { tonic-clonic seizures } \\
\text { due to a left parieto- } \\
\text { occipital FCD }\end{array}$ \\
\hline $\begin{array}{l}\text { Last seizure prior } \\
\text { to PET }\end{array}$ & $48 \mathrm{~h}$ & $36 \mathrm{~h}$ & 4 days & $3 \mathrm{~h}$ & 12 days \\
\hline Seizure & Focal unaware seizure & Focal aware seizure & Focal unaware seizure & Focal unaware seizure & Focal unaware seizure \\
\hline Anti-epileptic drugs & Yes & Yes & Yes & Yes & Yes \\
\hline Treatment-refractory & Yes & No & Yes & No & Yes \\
\hline Epilepsy $<$ surgery & No & $\begin{array}{l}3 \times \text { recurrent } \\
\text { ganglioglioma }\end{array}$ & No & No & No \\
\hline $\begin{array}{l}\text { Epilepsy due to } \\
\text { limbic encephalitis }\end{array}$ & No & No & No & Yes & No \\
\hline Lesion in MRI & No & Yes & No & Yes & Yes \\
\hline
\end{tabular}

$T L E$ temporal lobe epilepsy, $F C D$ focal cortical dysplasia

injected s.c. to help the rats recover. One rat died, and five rats fully recovered during the next days. In that period, rats were handfed with 1:1 amino acid solution (Aminoplasmal E, B.Braun, Germany) and $30 \%$ glucose solution until they ate normally and gained weight. Four of the five rats had developed spontaneous seizures by 24 days after KA titration. During this period, $\left[{ }^{18} \mathrm{~F}\right] \mathrm{FET}$ PET and MRI scans were performed regularly.

The experimental setup of the PTZ group is shown in Table 3. After a baseline MRI and $\left[{ }^{18}\right.$ F]FET PET, the PTZ kindling was performed three times per week for 8 weeks by i.p. injection of subthreshold doses of PTZ $(20-30 \mathrm{mg} / \mathrm{kg}$ BW) to increase seizures from class I in the first week to class $\mathrm{V}$ in the last week. During and after the kindling period, $\left[{ }^{18}\right.$ F]FET PET and MRI were performed regularly on seizure-free days. After a pause of several weeks, the still sensitized rats underwent additional 8 days of PTZ injections (one and two injections per day alternatingly), and two $\left[{ }^{18} \mathrm{~F}\right] \mathrm{FET}$ PET scans were performed on seizure days and seizure-free days, respectively.

The control rats underwent the same procedures but were injected with saline instead of KA or PTZ.

Severity of seizures was determined based on the Racine's scale [17] using five stages: (1) hyperactivity, restlessness, vibrissae twitching, mild facial automatisms; (2) strong facial automatisms, head nodding, head clonus, litter pushing; (3) clonic/tonic forelimbs, $>20 / 10$ min body jerks; (4) clonic/tonic generalized seizures with rearing; (5) clonic/tonic generalized seizures with loosing balance.

\section{PET Imaging with $\left[{ }^{18} F\right] F E T$}

$\left[{ }^{18} \mathrm{~F}\right] \mathrm{FET}$ was synthesized in-house as described elsewhere with a specific radioactivity of $>200 \mathrm{GBq} / \mu \mathrm{mol}$ [18]. PET imaging in rats was performed under isoflurane anesthesia. A venous catheter was inserted into the rats' tail vein, and animals were positioned in the field-of-view of the small animal Siemens INVEON scanner (Siemens-CTI) [19]. Body temperature and breathing rate were controlled. After a transmission scan (10 min), dynamic data acquisition was performed in 3D list mode for $47 \mathrm{~min}$ starting with injection of $20-30 \mathrm{MBq}\left[{ }^{18} \mathrm{~F}\right] \mathrm{FET}$ in saline, depending on the rats' weight, into the tail vein (bolus injection of $0.5 \mathrm{ml}$ in $1 \mathrm{~min}$ ). Emission data were framed into a dynamic sequence of $2 \times$ $0.5 \mathrm{~min}, 4 \times 1 \mathrm{~min}, 6 \times 3 \mathrm{~min}$, and $6 \times 4 \mathrm{~min}$ frames. Filtered back-projection (Ramp filter, cut-off $=0.5$ ) was applied to reconstruct 159 slices with an image voxel size of $0.7764 \times$ $0.7764 \times 0.796 \mathrm{~mm}^{3}$ (matrix size $128 \times 128 \times 159$ ). Images were corrected for random coincidences, scatter radiation, and attenuation.

All five patients fasted for at least $4 \mathrm{~h}$ before PET scanning, according to the German guidelines for brain tumor imaging using radiolabeled amino acid analogues [20]. PET imaging was performed on an ECAT Exact HR+ PET scanner (Siemens Medical Systems, Erlangen, Germany) in 3-dimensional mode (axial field of view, $15.5 \mathrm{~cm}$; image resolution, $6 \mathrm{~mm}$ ). The dynamic PET studies were acquired in frames of $5 \times 1 \mathrm{~min}, 5 \times 3 \mathrm{~min}$, and $4 \times 5 \mathrm{~min}$ for $40 \mathrm{~min}$ after intravenous injection of approximately $3 \mathrm{MBq} /$ $\mathrm{kg}$ body weight $\left[{ }^{18} \mathrm{~F}\right] \mathrm{FET}$. Iterative reconstruction with 16 subsets and 6 iterations without any filtering was applied; attenuation correction was based on the transmission scan.

\section{PET Data Analysis}

The analysis of the animal data was performed in summed images (18-47 min post-injection) using PMOD (Version 3.902, PMOD Technologies, Ltd.). The PET images of all 
Table 2. Experimental setup of the KA group. Racine class subscriptions refer to the seizure class which the rats exhibited during the previous injections

\begin{tabular}{|c|c|c|c|c|c|c|}
\hline & SUN & $\mathrm{MoN}$ & Tue & Wed & Thu & FrI \\
\hline W1 & \multirow[t]{4}{*}{ KA titration } & & & $\mathrm{PET}_{\text {Racine } \mathrm{V}}$ & $\mathrm{MR}_{\text {Racine } \mathrm{V}}$ & \\
\hline W2 & & & $\mathrm{MR}_{\text {interictal }}$ & $\mathrm{PET}_{\text {interictal }}$ & & \\
\hline W3 & & & & $\mathrm{PET}_{\text {interictal }}$ & & $\mathrm{MR}_{\text {interictal }}$ \\
\hline W4 & & & Spontaneous seizures in $4 / 5$ rats & $\mathrm{PET}_{\text {interictal/postictal }}$ & Sacrifice & \\
\hline
\end{tabular}

rats were fitted to PMOD's Px Rat (W.Schiffer) atlas of rat brain voxel-of-interest (VOIs) regions (Fig. 1). Some VOIs were fused to obtain the mean standardized uptake values (SUV) from the following regions: hippocampus, cerebellum, striatum/thalamus/septum, amygdala/entorhinal cortex, and frontolasso/moto/retrospinal cortex, and the mean of those regions. The MR images of the rats were co-registered to the PET/atlas images to check for correct placement of the rat atlas VOIs.

The PET scans of the patients were analyzed by visual evaluation of summed images (20-40 min post-injection) for alteration of $\left[{ }^{18} \mathrm{~F}\right] \mathrm{FET}$ uptake by two experienced nuclear physicians in consensus (G.S., C.F.).

\section{MR Imaging}

The rats were scanned on a small animal 9.4T MRI scanner using an in-house built circularly polarized birdcage rat head coil (diameter of $42 \mathrm{~mm}$ ) [21]. The MRI scans were started with acquiring scout images and carrying out standard adjustments, such as static magnetic field shimming and radiofrequency power calibration. $T_{1}$ weighted with and without contrast agent and $\mathrm{T}_{2}$-weighted images were then acquired using a 3D MP-RAGE and a turbo spin echo sequence, respectively. A venous access connected with a long tubing for contrast agent injection $(0.5 \mathrm{ml} / \mathrm{kg}$ gadopentetic acid, $0.5 \mathrm{mmol} / \mathrm{ml}$ ) was inserted into the tail vein. As in
PET, rats were anesthetized, and body temperature as well as breathing rate was continuously monitored and maintained.

\section{Immunohistochemistry}

Brains of the KA group, including two controls, were taken out, frozen in isopentane $\left(-50{ }^{\circ} \mathrm{C}\right)$ and cryo-cut in $20 \mu \mathrm{m}$ slices coronally. Slices were fixed with paraformaldehyde and subsequently stained for glial fibrillary acid protein (anti-GFAP, DAKO Z0334), microglia (anti-Iba1, abcam ab107159), and neurons (anti-NeuN, Millipore MAB377) using standard protocols for fixed cryoslices. Stained slices of KA-treated rats and healthy controls were evaluated for differences in the visually striking regions determined in PET and MRI.

\section{Statistics}

Descriptive statistics are provided as mean and standard deviation (SD). Two-way repeated measures ANOVAs with all pairwise multiple comparison procedures (Holm-Sidak method) were performed in the KA group as well as in the PTZ group with the factors week of treatment and treatment group (drug or control). Within the KA group, all four vehicle-injected rats could serve as control rats; within the PTZ group, only two of those four rats were suitable as controls. $P$ values of 0.05 or less were considered

Table 3. Experimental setup of the PTZ group. Racine class subscriptions refer to the seizure class which the rats exhibited during the previous injections

\begin{tabular}{|c|c|c|c|c|c|}
\hline & Mo & Tue & Wed & Thu & Fr \\
\hline W0 & & & $\mathrm{MR}_{\text {baseline }}$ & PET $_{\text {baseline }}$ & \\
\hline W1 & K1 & & $\mathrm{K} 2$ & $\mathrm{PET}_{\text {Racine I }}$ & K3 \\
\hline W2 & K4 & & K5 & PET $_{\text {Racine II }}$ & K6 \\
\hline W3 & K7 & & K8 & & K9 \\
\hline W4 & K10 & $\mathrm{PET}_{\text {Racine III }}$ & K11 & $\mathrm{MR}_{\text {Racine III }}$ & K12 \\
\hline W5 & K13 & & K14 & $\mathrm{PET}_{\text {Racine III-IV }}$ & K15 \\
\hline W6 & K16 & & K17 & PET $_{\text {Racine III-IV }}$ & K18 \\
\hline W7 & K19 & & $\mathrm{K} 20$ & $\mathrm{PET}_{\text {Racine IV }}$ & K21 \\
\hline W8 & K22 & & K23 & $\mathrm{PET}_{\text {Racine } \mathrm{V}}$ & K24 \\
\hline W9 & $\mathrm{PET}_{\text {Racine } \mathrm{V}}$ & $\mathrm{MR}_{\text {Racine } \mathrm{V}}$ & & & \\
\hline \multicolumn{6}{|l|}{ W10 } \\
\hline W11 & & & $\mathrm{MR}_{\text {interictal }}$ & $\mathrm{PET}_{\text {interictal }}$ & \\
\hline W20 & & & & & PTZ 1 \\
\hline W21 & PTZ $2+3$ & PTZ 4 & PTZ $5+6$ & PTZ 7 & PTZ $8+9$ \\
\hline W22 & PTZ 10 & PTZ $11+12$ & PTZ 13 PET $_{\text {postictal }}$ & & \\
\hline W23 & $\mathrm{PET}_{\text {interictal }}$ & $\mathrm{MR}_{\text {interictal }}$ & & & \\
\hline
\end{tabular}

$W$ week, $K$ injection of PTZ for kindling, $P T Z$ pentylenetetrazol injection in fully kindled rats 


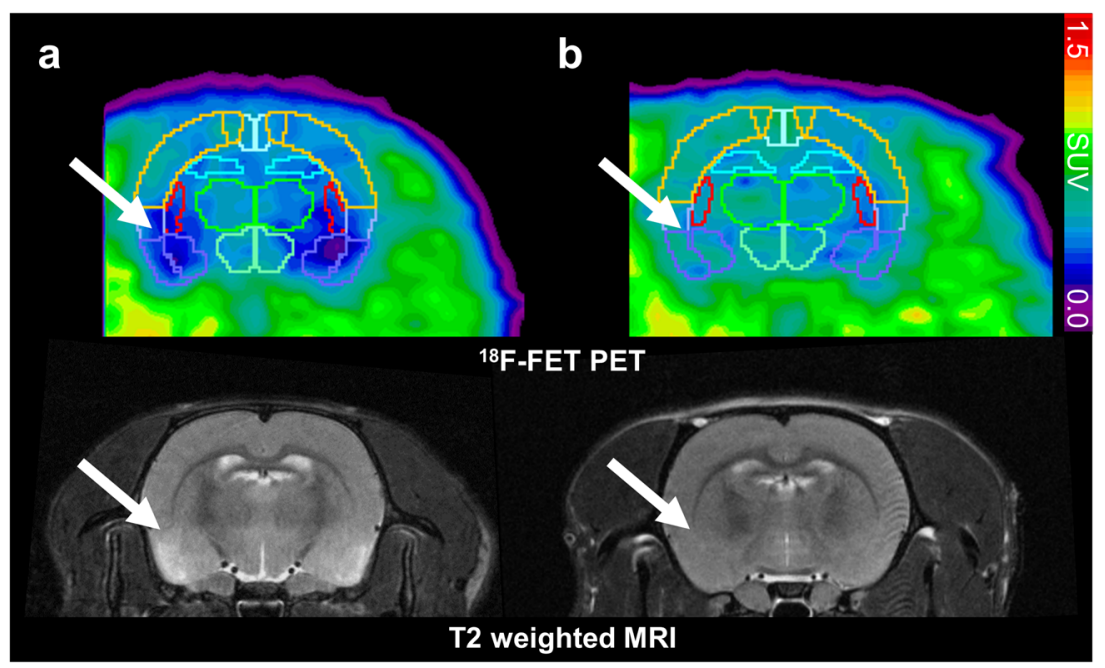

Fig. 1. $\left[{ }^{18} \mathrm{~F}\right] \mathrm{FET}$ PET (upper row) and $\mathrm{T}_{2}$-weighted MR scans (lower row) 3d, respectively 4d, after the status epilepticus (a) show alterations in the amygdala, piriform, and entorhinal region, compared with a healthy control rat (b). Regions of interest: light blue, hippocampus; violet, amygdala and entorhinal cortex; green, thalamus; red, striatum; yellow, fused frontolasso and moto and retrospinal cortex.

significant. Statistical analysis was performed using the SigmaPlot for Windows, Version 12.5.

\section{Results}

\section{Kainic Acid Model}

All six rats titrated with KA experienced 3 to $3.5 \mathrm{~h}$ of consecutive convulsive seizures; one rat died despite the injection with diazepam and ketamine.

In the images of the PET and MR scans 3 days (respectively 4 days) days after the SE, alterations could be detected visually in all five KA rats compared with the healthy controls (Fig. 1). Decreased $\left[{ }^{18}\right.$ F]FET uptake in the amygdala, piriform, and entorhinal region goes along with hyperintensities in $T_{2}$ images in the same regions as well as in the hippocampus. $T_{1}$ images with and without contrast enhancement were observed without pathological finding (data not shown). All visually detectable alterations normalized during the following 21 days and were no longer detectable.

Quantitative analysis of PET data (Fig. 2) confirmed decreased $\left[{ }^{18}\right.$ F]FET uptake 3 days after the SE compared with healthy controls. This decrease was most prominent in amygdala, but also significant in all evaluated brain regions. Ten days after the SE, three regions as well as the mean SUV of all regions were still significantly altered compared with the control. In the third and fourth week after SE, the decreased SUV had normalized compared with the controls. Likewise, a significant decrease in all regions was found in the first 2 weeks of the KA group compared with the third and fourth week of the same group (Fig. 2).

The immunohistochemistry of the KA rats showed alterations in the visually striking regions determined from
PET and MRI, the hippocampus, and amygdala region, as well as in some thalamic nuclei (Fig. 3). Profound astroglial activation was found in the CA1, CA2, CA3, and dentate gyrus of the hippocampus. Furthermore, the neuronal cell layer of the CA3 and hilus region was lost or severely damaged and showed high microglial activation (Fig. 3(1)). Accordingly, the intermediodorsal, mediodorsal, reuniens, and ventral thalamic nuclei showed astroglial and microglial activation and a decrease of neurons (Fig. 3(2)). In the visually striking amygdala region as defined in PET and MRI, the same widespread and profound astroglial and microglial activation in combination with neuronal loss was detected (Fig. 3(3)).

\section{PTZ Group}

All PTZ-kindled rats developed seizures that increased in severity according to Racine's scale over 8 weeks. One to two scales per week are listed in Table 3 on the day of imaging which are representative for every PTZ-kindled rat in that week. During the intensive seizure period in week 20-22, most of the seizures were class V, sometimes only class IV seizures occurred. Seizures lasted for $<1 \mathrm{~h}$ after PTZ injection, and no spontaneous seizures were observed in between the seizure periods or after the experiment.

In contrast to the KA group, no alterations were observed by visual inspection of PET and MR images (data not shown). Likewise, the quantitative PET evaluation over the whole period of testing did not show significant alterations of the SUV in any tested brain region when comparing PTZ rats with control rats or PTZ rats among themselves over the time. The SUV over the time of a representative midbrain region is shown in Fig. 4. 


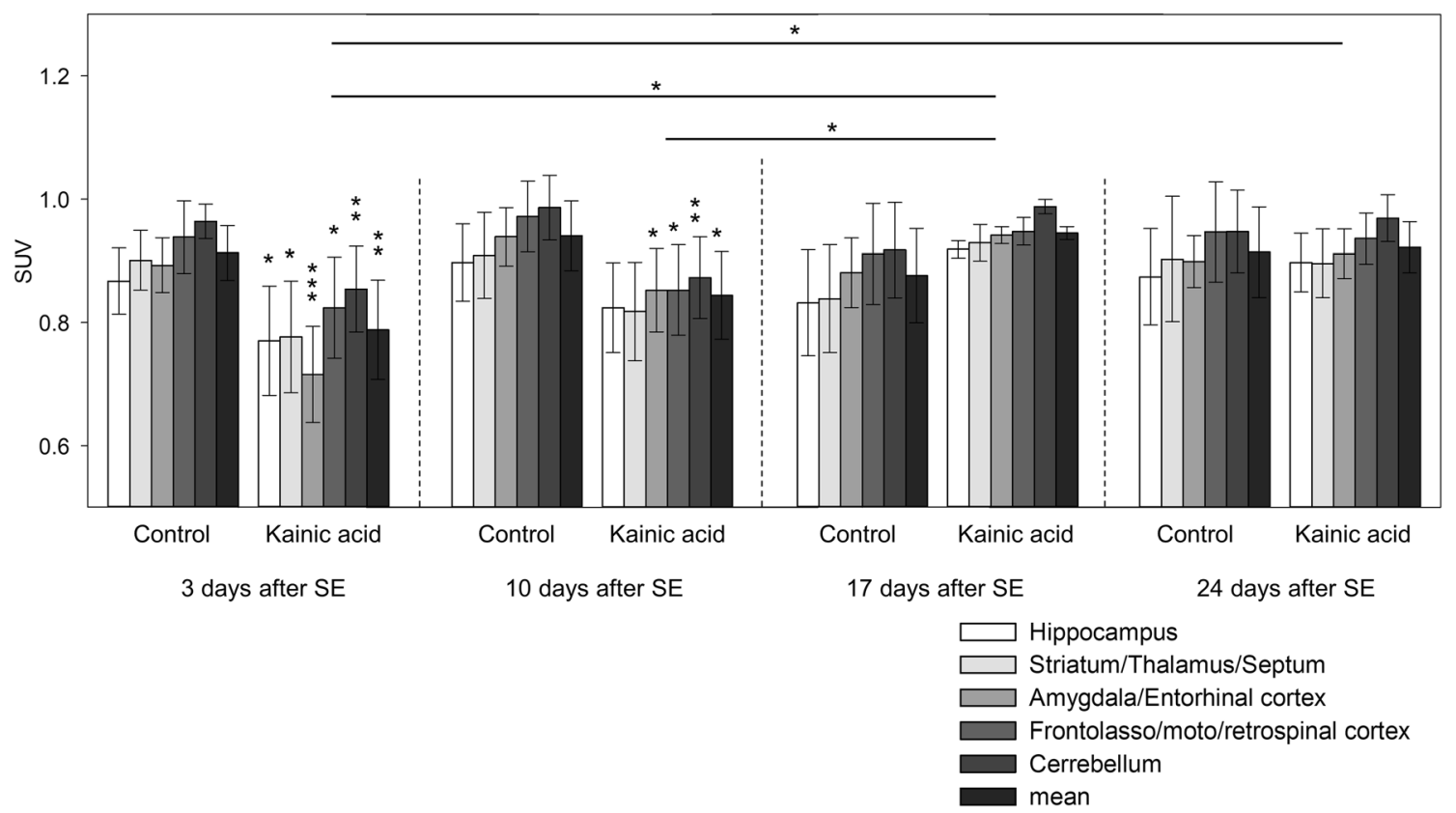

Fig. 2. Standardized uptake values (SUV) of $\left[{ }^{18} \mathrm{~F}\right] \mathrm{FET}$ uptake in the kainic acid model. Three days after severe SE, significantly decreased $\left[{ }^{18} \mathrm{~F}\right] \mathrm{FET}$ uptake was noted in all examined brain regions compared with control animals which persisted after 10 days (vertical asterisks). After 2 weeks, $\left[{ }^{18} \mathrm{~F}\right] \mathrm{FET}$ uptake recovered to normal values in all brain regions of epileptic rats (horizontal asterisks). ${ }^{*} p \leq 0.05 ;{ }^{* *} p \leq 0.01 ;{ }^{* * *} p \leq 0.001$.

\section{Epilepsy Patients}

In four of the five patients, a brain tumor as the cause of the focal epilepsy was excluded. The fifth patient, who was previously operated for ganglioglioma, did not show signs of tumor recurrence. No alteration of cerebral $\left[{ }^{18} \mathrm{~F}\right]$ FET uptake, neither increased nor decreased, was detected by visual evaluation in these patients. After the PET results of the animals were available, a second visual evaluation of the patient data was performed with special attention to the hippocampus and amygdala region. Again, no abnormality of cerebral $\left[{ }^{18}\right.$ F]FET uptake was observed. Fig. 5 shows the $\left[{ }^{18} \mathrm{~F}\right]$ FET PET and MRI scans of a patient with bilateral temporal lobe epilepsy (TLE).

\section{Discussion}

$\left[{ }^{18} \mathrm{~F}\right] \mathrm{FET}$ is one of the most widely used amino acid tracers for brain tumor diagnostics. The tracer has a wide diagnostic spectrum, including differential diagnosis, the evaluation of tumor extent, differentiation of tumor progress from treatment-related changes, and therapy monitoring. Therefore, the possibility of unspecific tracer uptake has always been an important field of research [4, 5, 22]. One of those pitfalls which could have considerable consequences for clinical application of $\left[{ }^{18} \mathrm{~F}\right] \mathrm{FET}$ may be the accumulation in epileptic foci especially in the postictal or interictal phase [12]. This phenomenon has not only been reported for $\left[{ }^{18} \mathrm{~F}\right] \mathrm{FET}$, but also for ${ }^{11} \mathrm{C}$-methonine [23-25], the longest established amino acid tracer for brain tumor imaging, which is taken up via the same amino acid transporter system LAT1/LAT2 as $\left[{ }^{18}\right.$ F]FET [26-28].

In this study, this issue was systematically investigated, and no evidence for a longer lasting $\left[{ }^{18} \mathrm{~F}\right] \mathrm{FET}$ accumulation in the postictal of interictal state was found neither in animal models nor in patients suggesting that epileptic seizures per se do not appear to be a major cause of pitfall for brain tumor diagnostics.

It has to be discussed to what extent the animal experiments are representative for the clinical scenario in humans. The two rat epilepsy models in our study are chemically induced with systemic injections, but differ in several aspects. KA is an agonist of kainate receptors, one type of inotropic glutamate receptors, and thus leads to excitotoxic lesions, especially in the hippocampus and amygdala [29, 30] (Fig. 3). The spontaneous seizures that occur due to structural rearrangements several weeks after the initial severe SE are considered as a suitable model for chronic epilepsy similar to TLE $[13,31]$. Thus, this model was chosen to determine $\left[{ }^{18} \mathrm{~F}\right] \mathrm{FET}$ accumulation after severe SE in early stage ( $<3$ days) including disruption of the blood brain barrier (BBB) [32, 33], in the latent period without seizures, and in the beginning of the chronic phase with spontaneous seizures. All phases are accompanied by different levels of structural changes including edema, neuronal loss, and microglia activation. VOIs for quantitative evaluation were located in the hippocampus, amygdala, and entorhinal cortex according to the predominant pathology in the KA model and TLE. VOIs in areas with milder pathology included cortical areas, a midbrain region 

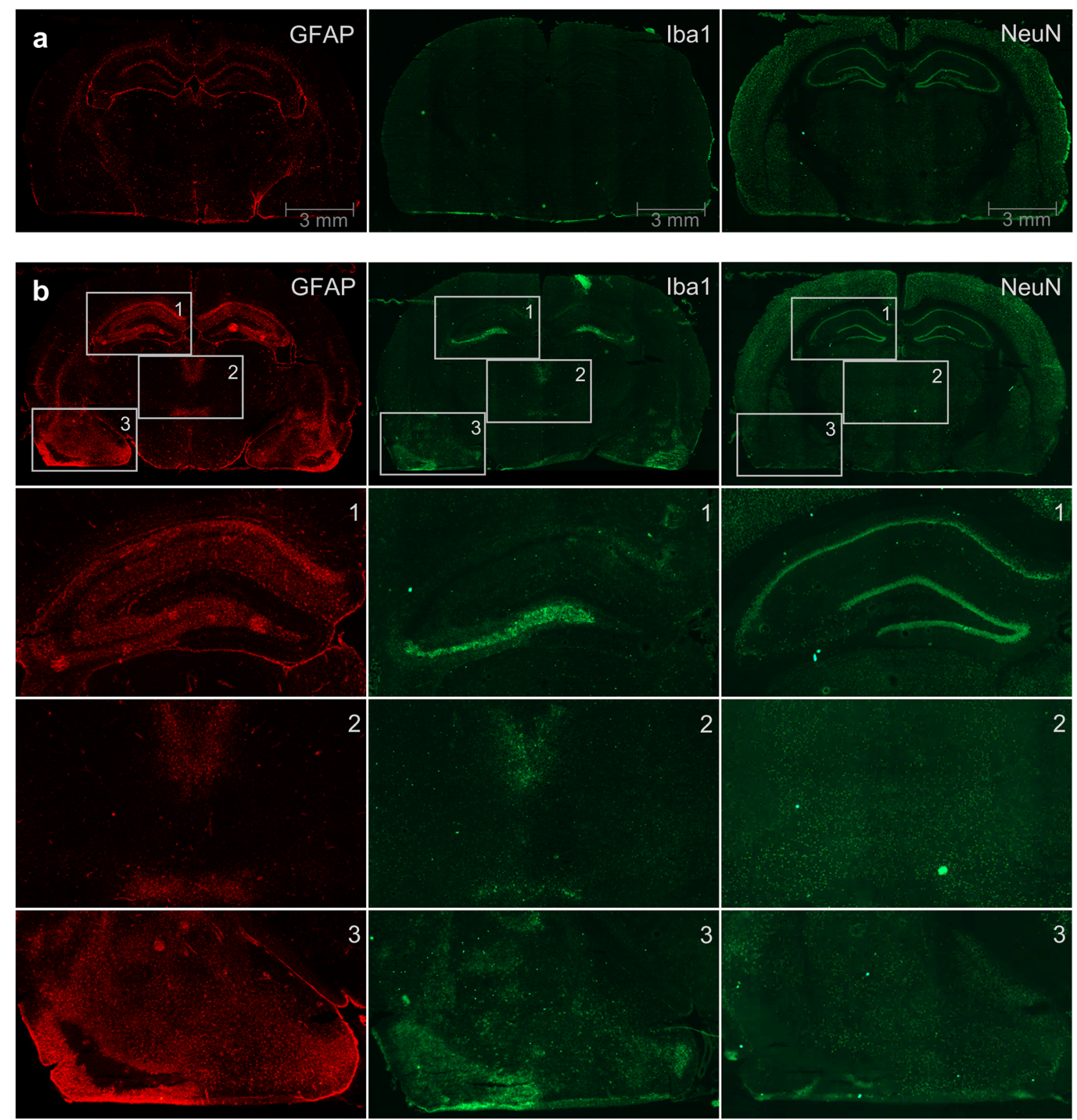

Fig. 3. Immunofluorescence staining of a control rat (a) and a kainic acid status epilepticus rat (b). Consecutive slices were stained for activated astrocytes (GFAP), activated microglia (Iba1), and neurons (NeuN) and visually examined for seizurerelated changes. In the hippocampus (1), widespread astrocyte activation is visibly, while microglia are restricted to the lower region (CA3 region) where a loss of neurons was detected. Similar findings-astrocyte and microglial activation accompanied by a loss of neurons-can be detected in thalamic nuclei (intermediodorsal, mediodorsal, reuniens, and ventral thalamic nucleus); (2) as well as in the amygdala and piriform area (3).

containing the thalamic nuclei and the septum as well as the cerebellum [34, 35]. We observed no elevated but on the contrary a pronounced decrease of $\left[{ }^{18} \mathrm{~F}\right] \mathrm{FET}$ uptake 3 days after SE in the amygdala/entorhinal region with concomitant hyperintensities of the $T_{2}$ MRI signal and severe tissue damage, as seen 25 days after the SE by tissue staining (Fig. 3 ). The hyperintense $T_{2}$ signal indicates vasogenic and cytotoxic edema, a state that peaks around $24 \mathrm{~h}$ after KA treatment and subsequently diminishes [36]. In these early hours after the SE, the breakdown of the BBB is most pronounced [32, 37, 38]. In our experiments, we observed no contrast enhancement but more sensitive methods have demonstrated $\mathrm{BBB}$ leakage in the KA model as late as 6 weeks after SE [32]. The low $\left[{ }^{18}\right.$ F]FET uptake in our experiments is in opposition to the assumptions made by Hutterer and colleagues [12], who presumed a positive correlation between edema, contrast enhancement, and $\left[{ }^{18}\right.$ F $]$ FET uptake.

In contrast to the KA model, injection of the GABA antagonist PTZ is a kindling model that mimics mild 


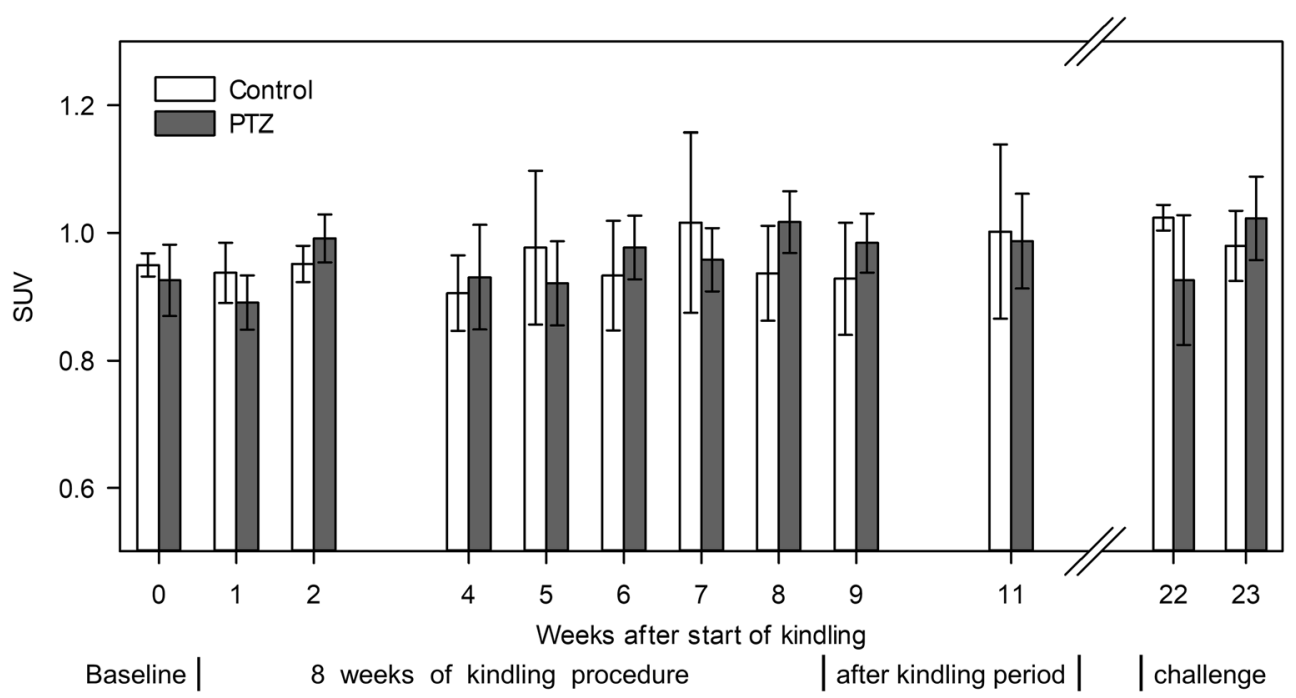

Fig. 4. Time line of $\left[{ }^{18}\right.$ F]FET PET uptake in the PTZ model, starting with the baseline scan and ending with the PTZ challenge 23 weeks later. Comparing the SUV of PTZ rats with the control group using a midbrain region containing thalamic, striatal, and septum regions, no alterations in tracer uptake during or after the kindling period or during the PTZ challenge were detected. Likewise, within the PTZ group, no significant changes of the SUV over the time were observed.

absence to clonic-tonic SE with tissue alterations only in later stages, especially in the hippocampus [39, 40]. Interestingly, and unlike in the KA model, seizures of the PTZ model did not lead to an altered $\mathrm{T}_{2}$ signal or $\left[{ }^{18} \mathrm{~F}\right] \mathrm{FET}$ uptake at any seizure level, although there are reports about altered $\mathrm{T}_{2}$ signals in late stages of PTZ-kindled rats [41].

While MR findings indicating an edema normalized during the 4 weeks after the SE regardless of the level of tissue damage, neuronal loss was accompanied by massive microglial and astrocyte activation. According to the neuronal loss especially in the amygdala and hippocampus area (Fig. 3), the recovery of decreased $\left[{ }^{18}\right.$ F]FET uptake to the baseline level in those areas was surprising. A possible explanation might be the microglia and astrocyte activation, which were shown to slightly increase the $\left[{ }^{18} \mathrm{~F}\right] \mathrm{FET}$ uptake in other pathological states [42]. Decreased uptake due to neuronal loss and increased uptake due to activation processes in the same region cannot be separated in PET due to relatively low spatial resolution and partial volume effects. Hence, uptake appears to be within normal range.

Although the experiments cover the typical pathophysiological changes in cerebral seizures to a very large extent, the animal models have some limitations, e.g., much shorter medical history and generalized seizures due to systemic exposure while patients suffer more frequently from focal seizures, in particular when seizures are tumor-associated. Furthermore, we did not scan any subjects in ictal states; thus, we cannot make a statement concerning short-term $\left[{ }^{18} \mathrm{~F}\right] \mathrm{FET}$ accumulation in ictal state for patients or rats. Finally, due to few controls $(n=2)$ in the PTZ group, minor changes in the FET accumulation could have been missed. Since the PTZ model is known to show only minor structural changes in contrast to the kainic acid model, it is unlikely that the overall conclusions are affected.

We therefore tried to substantiate the results with patient data and identified five patients in our database who underwent $\left[{ }^{18}\right.$ F]FET PET $48 \mathrm{~h}$ to 12 days after seizures for the exclusion of brain tumor-related epilepsy. None of the patients could currently be diagnosed with a brain tumor. Patient diagnosis included TLE with focal aware and unaware as well as focal to bilateral tonic-clonic seizures; two patients were diagnosed with seizures due to structural pathologies. Thus, these diagnoses included some seizure types that may not have been covered by the animal models. No abnormalities of cerebral $\left[{ }^{18} \mathrm{~F}\right] \mathrm{FET}$ uptake were noted, neither in limbic structures as observed in the animal experiments, nor gyral uptake as reported by Hutterer and colleagues [12].

Thus, the two preclinical models and patient data cover a wide range of seizure classes with and without tissue alterations, and PET scans were performed in interictal as well as postictal states. In no case, increased $\left[{ }^{18} \mathrm{~F}\right] \mathrm{FET}$ uptake comparable with that in the previous reports was seen and a further elucidation of those findings was not possible. Noticeably, in the existent reports of increased $\left[{ }^{18} \mathrm{~F}\right] \mathrm{FET}$ and ${ }^{11} \mathrm{C}$-MET uptake, the seizures were in some cases associated with cortical dysplasia $[23,25]$, which has distinct histological and structural features [43]. We therefore assume that the observed cases in those reports represent a very rare constellation which was not found in the patient population of this study. This is also supported by the fact that in more than 6000 patients examined with $\left[{ }^{18}\right.$ F]FET PET in our institute and in a retrospective study examining long-term epilepsy associated tumors with $\left[{ }^{18} \mathrm{~F}\right] \mathrm{FET}[44]$, a non-tumor- 


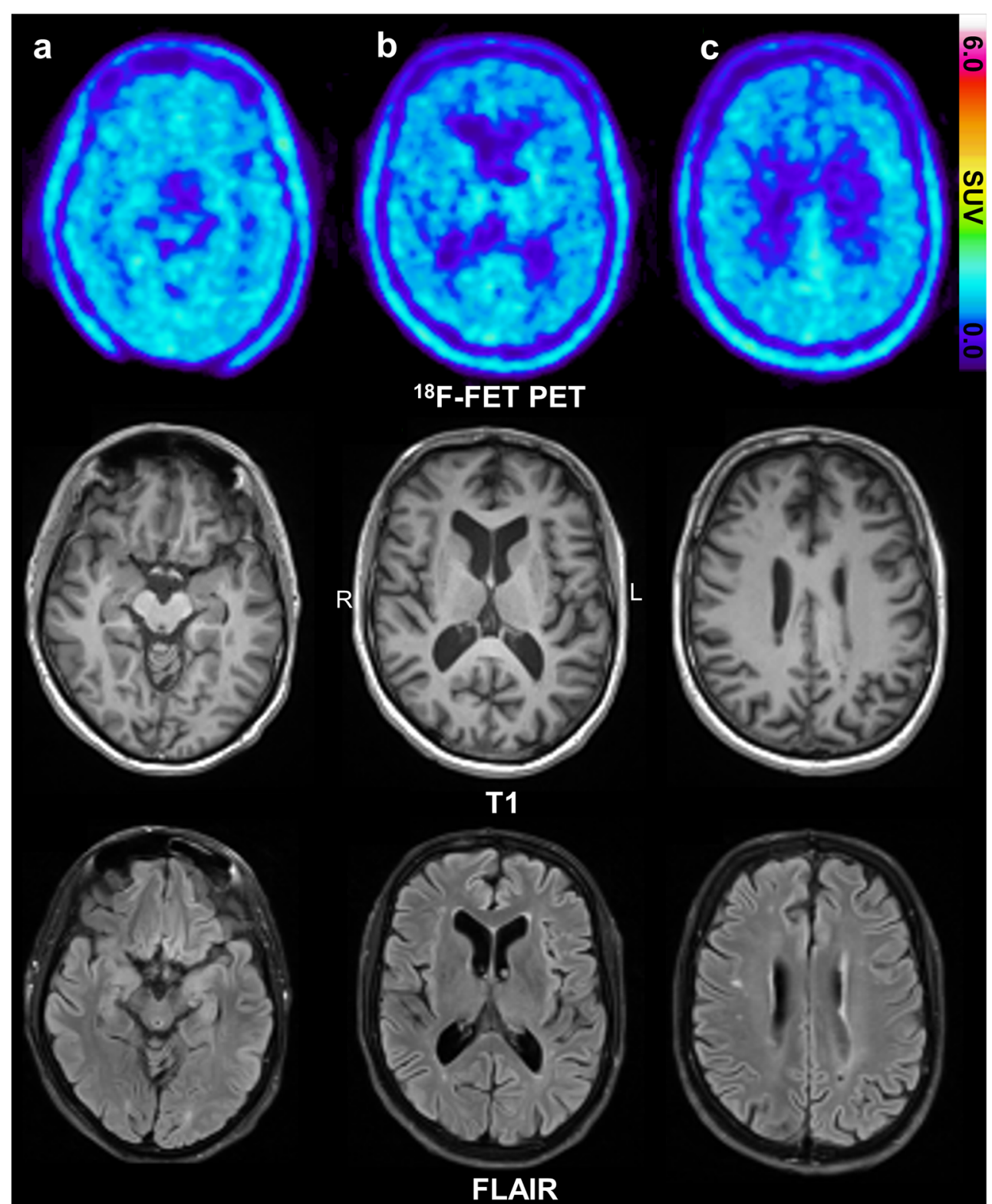

Fig. 5. $\left[{ }^{18}\right.$ F]FET PET and MRI of patient no. 4 (Table 1) with bilateral temporal lobe epilepsy with nocturnal focal unaware and focal to bilateral tonic-clonic seizures. No abnormalities in $\left[{ }^{18} \mathrm{~F}\right] \mathrm{FET}$ uptake are visible. Representative horizontal sections at the level of the temporal lobe (a), the basal ganglia (b), or just below the centrum semiovale (c). Note a small subcortical lesion in the FLAIR sequence in the right hemisphere (c).

related, reversible $\left[{ }^{18} \mathrm{~F}\right] \mathrm{FET}$ accumulation in connection with epileptic seizures has not been noticed.

\section{Conclusion}

Our observation of normal or decreased cerebral $\left[{ }^{18} \mathrm{~F}\right] \mathrm{FET}$ uptake in two rat models of different grades of seizure and tissue damage and in five patients with different forms of epilepsy indicate that epileptic seizures per se do not cause longer lasting increased $\left[{ }^{18} \mathrm{~F}\right] \mathrm{FET}$ accumulation. Therefore, it is unlikely that $\left[{ }^{18} \mathrm{~F}\right] \mathrm{FET}$ accumulation due to epileptic seizures represents a major pitfall in the diagnostics of brain tumors. Furthermore, it can be concluded that $\left[{ }^{18}\right.$ F]FET PET is not a suitable method to localize epileptic foci.

Acknowledgments. Open Access funding provided by Projekt DEAL. The authors wish to thank Erika Wabbals, Silke Grafmüller, and Sascha Rehbein for technical assistance in radiosynthesis of $\left[{ }^{18} \mathrm{~F}\right] \mathrm{FET}$.

Compliance with Ethical Standards

\section{Conflict of Interest}

The authors declare that they have no conflict of interest. 


\section{Ethical Approval}

All procedures performed in studies involving human participants were in accordance with the ethical standards of the institutional and national research committee and with the 1964 Helsinki declaration and its later amendments or comparable ethical standards.

All applicable international, national, and institutional guidelines for the care and use of animals were followed.

\section{Informed Consent}

Informed consent was obtained from all individual participants included in the study.

Open Access This article is licensed under a Creative Commons Attribution 4.0 International License, which permits use, sharing, adaptation, distribution and reproduction in any medium or format, as long as you give appropriate credit to the original author(s) and the source, provide a link to the Creative Commons licence, and indicate if changes were made. The images or other third party material in this article are included in the article's Creative Commons licence, unless indicated otherwise in a credit line to the material. If material is not included in the article's Creative Commons licence and your intended use is not permitted by statutory regulation or exceeds the permitted use, you will need to obtain permission directly from the copyright holder. To view a copy of this licence, visit http:// creativecommons.org/licenses/by/4.0/.

\section{Key Points}

Question: This study was designed to clarify whether $\left[{ }^{18} \mathrm{~F}\right] \mathrm{FET}$ brain uptake is increased due to seizure activity.

Pertinent findings: Preclinical animal testing as well as retrospective patient evaluation did not reveal increased $\left[{ }^{18} \mathrm{~F}\right] \mathrm{FET}$ brain uptake due to seizure activity.

Implications for patient care: Increased $\left[{ }^{18} \mathrm{~F}\right] \mathrm{FET}$ brain uptake due to seizure activity is a very rare phenomenon and thus no major pitfall in brain tumor diagnostics.

\section{References}

1. Langen KJ, Galldiks N, Hattingen E, Shah NJ (2017) Advances in neuro-oncology imaging Nature reviews. Neurology 13:279-289

2. Albert NL, Weller M, Suchorska B, Galldiks N, Soffietti R, Kim MM, la Fougere C, Pope W, Law I, Arbizu J, Chamberlain MC, Vogelbaum M, Ellingson BM, Tonn JC (2016) Response Assessment in NeuroOncology working group and European Association for NeuroOncology recommendations for the clinical use of PET imaging in gliomas. Neuro-oncology 18:1199-1208

3. Langen KJ, Watts C (2016) Neuro-oncology: amino acid PET for brain tumours - ready for the clinic? Nat Rev Neurol 12:375-376

4. Galldiks N, Langen K, Holy R, Pinkawa M, Stoffels G, Nolte K, Kaiser H, Filss C, Fink G, Coenen H, Eble M, Piroth M (2012) Assessment of treatment response in patients with glioblastoma using [18F]fluoroethyl-L-tyrosine PET in comparison to MRI Journal of nuclear medicine : official publication. Soc Nucl Med 53:1048-1057

5. Pichler R, Dunzinger A, Wurm G, Pichler J, Weis S, Nussbaumer K, Topakian R, Aigner RM (2010) Is there a place for FET PET in the initial evaluation of brain lesions with unknown significance? Eur $\mathrm{J}$ Nucl Med Mol Imaging 37:1521-1528

6. Calcagni ML, Galli G, Giordano A, Taralli S, Anile C, Niesen A, Baum RP (2011) Dynamic O-(2-[18F]fluoroethyl)-L-tyrosine (F-18 FET) PET for glioma grading: assessment of individual probability of malignancy. Clin Nucl Med 36:841-847

7. Jansen NL, Suchorska B, Wenter V, Schmid-Tannwald C, Todica A, Eigenbrod S, Niyazi M, Tonn JC, Bartenstein P, Kreth FW, la Fougere C (2015) Prognostic significance of dynamic 18F-FET PET in newly diagnosed astrocytic high-grade glioma Journal of nuclear medicine : official publication. Soc Nucl Med 56:9-15

8. Kurzwelly D, Herrlinger U, Simon M (2010) Seizures in patients with low-grade gliomas-incidence, pathogenesis, surgical management, and pharmacotherapy. Adv Tech Stand Neurosurg 35:81-111

9. Chassoux F, Landre E (2017) Prevention and management of postoperative seizures in neuro-oncology. Neurochirurgie 63:197-203
10. Vecht C, Royer-Perron L, Houillier C, Huberfeld G (2017) Seizures and anticonvulsants in brain tumours: frequency, mechanisms and anti-epileptic management. Curr Pharm Des 23:6464-6487

11. Maschio M (2012) Brain tumor-related epilepsy. Curr Neuropharmacol 10:124-133

12. Hutterer M, Ebner Y, Riemenschneider MJ, Willuweit A, McCoy M, Egger B, Schroder M, Wendl C, Hellwig D, Grosse J, Menhart K, Proescholdt M, Fritsch B, Urbach H, Stockhammer G, Roelcke U, Galldiks N, Meyer PT, Langen KJ, Hau P, Trinka E (2017) Epileptic activity increases cerebral amino acid transport assessed by $18 \mathrm{~F}-$ fluoroethyl-1-tyrosine amino acid PET: a potential brain tumor mimic. J Nucl Med 58:129-137

13. Dudek FE, Clark S, Williams PA, Grabenstatter HL (2006) Kainatinduced status epilepticus. In: Pitkänen A, Schwartzkroin PA, Moshé SL (eds) Models of seizures and epilepsy. Elsevier Academic Press, Burlington

14. Gilbert ME, Goodman JH (2006) Chemical kindling. In: Pitkänen A, Schwartzkroin PA, Moshé SL (eds) Models of seizures and epilepsy. Elsevier Academic Press, Burlington

15. Hellier JL, Dudek FE (2005) Chemoconvulsant model of chronic spontaneous seizures. Curr Protoc Neurosci Chapter 9:Unit 9-Unit19

16. Vermoesen K, Smolders I, Massie A, Michotte Y, Clinckers R (2010) The control of kainic acid-induced status epilepticus. Epilepsy Res 90:164-166

17. Racine RJ (1972) Modification of seizure activity by electrical stimulation. II. Motor seizure. Electroencephalogr Clin Neurophysiol 32:281-294

18. Hamacher K, Coenen HH (2002) Efficient routine production of the 18F-labelled amino acid O-2-18F fluoroethyl-L-tyrosine. Appl Radiat Isot 57:853-856

19. Bao Q, Newport D, Chen M, Stout DB, Chatziioannou AF (2009) Performance evaluation of the inveon dedicated PET preclinical tomograph based on the NEMA NU-4 standards. J Nucl Med 50:401-408

20. Langen KJ, Bartenstein P, Boecker H, Brust P, Coenen HH, Drzezga A, Grunwald F, Krause BJ, Kuwert T, Sabri O, Tatsch K, Weber WA, Schreckenberger M (2011) German guidelines for brain tumour imaging by PET and SPECT using labelled amino acids Nuklearmedizin. Nucl Med 50:167-173

21. Choi CH, Ha Y, Veeraiah P, Felder J, Mollenhoff K, Shah NJ (2016) Design and implementation of a simple multinuclear MRI system for ultra high-field imaging of animals. J Magn Reson 273:28-32

22. Pöpperl G, Kreth FW, Mehrkens JH, Herms J, Seelos K, Koch W, Gildehaus FJ, Kretzschmar HA, Tonn JC, Tatsch K (2007) FET PET for the evaluation of untreated gliomas: correlation of FET uptake and uptake kinetics with tumour grading. Eur J Nucl Med Mol Imaging 34:1933-1942

23. Madakasira PV, Simkins R, Narayanan T, Dunigan K, Poelstra RJ, Mantil J (2002) Cortical dysplasia localized by [11C]methionine positron emission tomography: case report. AJNR Am J Neuroradiol 23:844-846

24. Lopci E, Bello L, Chiti A (2014) (11)C-Methionine uptake in secondary brain epilepsy. Rev Esp Med Nucl Imagen Mol 33:234-236

25. Sasaki M, Kuwabara Y, Yoshida T, Fukumura T, Morioka T, Nishio S, Fukui M, Masuda K (1998) Carbon-11-methionine PET in focal cortical dysplasia: a comparison with fluorine-18-FDG PET and technetium-99m-ECD SPECT. Journal of nuclear medicine : official publication. Soc Nucl Med 39:974-977

26. Okubo S, Zhen HN, Kawai N, Nishiyama Y, Haba R, Tamiya T (2010) Correlation of L-methyl-11C-methionine (MET) uptake with L-type amino acid transporter 1 in human gliomas. J Neuro-Oncol 99:217-225

27. Langen KJ, Jarosch M, Muhlensiepen H, Hamacher K, Broer S, Jansen P, Zilles K, Coenen HH (2003) Comparison of fluorotyrosines and methionine uptake in F98 rat gliomas. Nucl Med Biol 30:501-508

28. Langen KJ, Broer S (2004) Molecular transport mechanisms of radiolabeled amino acids for PET and SPECT. Journal of nuclear medicine : official publication. Soc Nucl Med 45:1435-1436

29. Nadler JV, Perry BW, Cotman CW (1978) Intraventricular kainic acid preferentially destroys hippocampal pyramidal cells. Nature 271:676-677

30. Ben-Ari Y (1985) Limbic seizure and brain damage produced by kainic acid: mechanisms and relevance to human temporal lobe epilepsy. Neuroscience 14:375-403 
31. Levesque M, Avoli M (2013) The kainic acid model of temporal lobe epilepsy. Neurosci Biobehav Rev 37:2887-2899

32. van Vliet EA, Otte WM, Gorter JA, Dijkhuizen RM, Wadman WJ (2014) Longitudinal assessment of blood-brain barrier leakage during epileptogenesis in rats. A quantitative MRI study. Neurobiol Dis 63:74-84

33. van Vliet EA, Otte WM, Wadman WJ, Aronica E, Kooij G, de Vries HE, Dijkhuizen RM, Gorter JA (2016) Blood-brain barrier leakage after status epilepticus in rapamycin-treated rats I: magnetic resonance imaging. Epilepsia 57:59-69

34. Bartolomei F, Khalil M, Wendling F, Sontheimer A, Regis J, Ranjeva JP, Guye M, Chauvel P (2005) Entorhinal cortex involvement in human mesial temporal lobe epilepsy: an electrophysiologic and volumetric study. Epilepsia 46:677-687

35. Nitecka L, Tremblay E, Charton G, Bouillot JP, Berger ML, Ben-Ari Y (1984) Maturation of kainic acid seizure-brain damage syndrome in the rat. II. Histopathological sequelae. Neuroscience 13:1073-1094

36. Liachenko S, Ramu J, Konak T, Paule MG, Hanig J (2015) Quantitative assessment of MRI T2 response to kainic acid neurotoxicity in rats in vivo. Toxicol Sci 146:183-191

37. Roch C, Leroy C, Nehlig A, Namer IJ (2002) Magnetic resonance imaging in the study of the lithium-pilocarpine model of temporal lobe epilepsy in adult rats. Epilepsia 43:325-335
38. Zucker DK, Wooten GF, Lothman EW (1983) Blood-brain barrier changes with kainic acid-induced limbic seizures. Exp Neurol 79:422-433

39. Samokhina E, Samokhin A (2018) Neuropathological profile of the pentylenetetrazol (PTZ) kindling model. Int J Neurosci 128:10861096

40. Pohle W, Becker A, Grecksch G, Juhre A, Willenberg A (1997) Piracetam prevents pentylenetetrazol kindling-induced neuronal loss and learning deficits. Seizure 6:467-474

41. Fang F, Lei H (2010) Increased hippocampal T2 in a rat model of pentylenetetrazol-induced kindling correlates with seizure scores. J Neurol Sci 292:16-23

42. Stegmayr C, Willuweit A, Lohmann P, Langen KJ (2019) O-(2-[18F]fluoroethyl)-L-tyrosine (FET) in neurooncology: a review of experimental results. Curr Radiopharm 12:201-210

43. Taylor DC, Falconer MA, Bruton CJ, Corsellis JA (1971) Focal dysplasia of the cerebral cortex in epilepsy. J Neurol Neurosurg Psychiatry 34:369-387

44. Kasper BS, Struffert T, Kasper EM, Fritscher T, Pauli E, Weigel D, Kerling F, Hammen T, Graf W, Kuwert T, Prante O, Lorber B, Buchfelder M, Doerfler A, Schwab S, Stefan H, Linke R (2011) 18Fluoroethyl-L-tyrosine-PET in long-term epilepsy associated glioneuronal tumors. Epilepsia 52:35-44 